DOI 10.12737/article_5a84427e9223e2.10424083

УДК 635.656
РЕАКЦИЯ СОРТОВ ГОРОХА ПОСЕВНОГО НА АБИОТИЧЕСКИЕ УСЛОВИЯ Фатыхов И.Ш., Корепанова Е.В., Сундукова Я.Н.

Реферат. Проблема реакции сортов или гибридов полевых культур на абиотические условия всегда была ключевой в растениеводстве. С появлением новых сортов гороха посевного необходимы дальнейшие исследования в данном направлении. Цель исследований - определить в конкурсном сортоиспытании реакцию сортов гороха посевного на абиотические условия формированиям урожайности на госсортоучстках Удмуртской Республики. Задачи исследований: анализ урожайности семи сортов гороха посевного на четырех госсортоучастках; выявить наиболее продуктивные сорта в разных абиотических условиях: Объект исследований: сорта гороха посевного Аксайский усатый, Красноус, Марафон, Памяти Хангильдина, Стабил, Томас, Ямал 2.

Ключевые слова: абиотические условия, реакция сорта, сортоиспытание.

Введение. Реакция сортов формированием урожайности на госсортоучастках Удмуртской Республики была разной. На Балезинском ГСУ наиболее высокую среднюю урожайность обеспечили сорта Стабил и Красноус, на Увинском ГСУ - Стабил, на Сарапульском ГСУ - Аксайский усатый, на Можгинском ГСУ - Марафон.

Под реакцией сельскохозяйственных культур понимается процесс или результат любых изменений в структуре и функциях растения. Проблема реакции сортов или гибридов полевых культур на абиотические условия всегда была ключевой в растениеводстве [1]. Раскрытие особенностей и закономерностей реакции сортов гороха посевного занимает центральное место в поиске наиболее эффективных путей управления формированием урожайности $[2,3,4,5,6,7,8,9,10]$. С появлением новых сортов гороха посевного необходимы дальнейшие исследования в данном направлении.

Цель исследований - определить в конкурсном сортоиспытании реакцию сортов гороха посевного на абиотические условия формированием урожайности на госсортоучстках Удмуртской Республики.

Задачи исследований:

- анализ урожайности семи сортов гороха посевного на четырех госсортоучастках;

- выявить наиболее продуктивные сорта в разных абиотических условиях;
Объект исследований: сорта гороха посевного Аксайский усатый, Красноус, Марафон, Памяти Хангильдина, Стабил, Томас, Ямал 2.

Условия и методика проведения исследований. Агрохимическая характеристика пахотного слоя опытных участков приведена в таблице 1.

Результаты исследований. Реакция сортов на абиотические условия формированием зерна на каждом госсортоучастке была разной. На Балезинском ГСУ в 2014 г. наибольшую урожайность имели сорта Стабил - 19,1 ц/га и Красноус - 18,4 ц/га (табл. 2).

В 2015 г. наиболее продуктивным были сорта Ямал - 32,1 ц/га, Томас - 27,7 ц/га, Красноус - 26,1 ц/га. Урожайность выше 20 ц/ га в 2016 г. сформировали сорта Ямал 2 - 24,3 ц/га, Томас - 21,3 ц/га, Памяти Хангильдина 20,9 ц/га, Марафон - 20,2 ц/га. В среднем за три года урожайность сорта Красноус составила 21,4 ц/га, Стабил - 21,1 ц/га, Ямал 2 - 20,9 ц/га.

На Увинском ГСУ в 2014 г. наиболее урожайными оказались Томас - 28,9 ц/га, Стабил - 28,0 ц/га, Аксайский усатый - 27,4 ц/га. В 2015 г. преимущество по урожайности 23,3 ц/ га имел сорт Стабил. Урожайность выше 15,0 ц/га. В 2016 г. имели Памяти Хангильдина 15,9 ц/га и Аксайский усатый - 15,2 ц/га. За исследуемые годы испытаний на Увинском ГСУ наибольшую продуктивность обеспечили

Таблица 1 - Агрохимическая характеристика пахотного слоя почв опытных участков

\begin{tabular}{|c|c|c|c|c|}
\hline \multirow[t]{2}{*}{ Почва } & \multirow[t]{2}{*}{ Гумус, \% } & \multirow[t]{2}{*}{$\mathrm{pH}_{\mathrm{KCl}}$} & \multicolumn{2}{|c|}{$\begin{array}{c}\text { Подвижный элемент, } \\
\text { мг/кг почвы }\end{array}$} \\
\hline & & & $\mathrm{P}_{2} \mathrm{O}_{5}$ & $\mathrm{~K}_{2} \mathrm{O}$ \\
\hline \multicolumn{5}{|l|}{ Сарапульский ГСУ } \\
\hline Лесная оподзоленная среднесуглинистая & $2,8-3,5$ & $\begin{array}{c}5,2- \\
6,1\end{array}$ & $120-300$ & $110-250$ \\
\hline \multicolumn{5}{|l|}{ Балезинский ГСУ } \\
\hline Дерново-сильноподзолистая средне и тяжелосуглинистая & $2,0-3,0$ & $4,6-6,0$ & $26-412$ & $50-300$ \\
\hline \multicolumn{5}{|l|}{ Глазовский ГСУ } \\
\hline Дерново-среднеподзолистая среднесуглинистая & $1,7-3,1$ & $5,0-6,5$ & $100-250$ & $81-300$ \\
\hline \multicolumn{5}{|l|}{ Можгинский ГСУ } \\
\hline Дерново-среднеподзолистая среднесуглинистая & $2,1-3,1$ & $4,6-6,0$ & $40-400$ & $30-300$ \\
\hline
\end{tabular}


СЕЛЬСКОХОЗЯЙСТВЕННЫЕ НА УКИ

Таблица 2 - Урожайность сортов гороха посевного на госсортоучастках

Удмуртской Республики.

\begin{tabular}{|c|c|c|c|c|}
\hline \multirow{2}{*}{ Сорт } & \multicolumn{4}{|c|}{ Урожайность, ц/га } \\
\hline & 2014 & 2015 & 2016 & средняя \\
\hline \multicolumn{5}{|c|}{ Балезинский ГСУ } \\
\hline Аксайский усатый & 9,8 & 17,3 & 17,0 & 14,7 \\
\hline Красноус & 18,4 & 26,1 & 19,7 & 21,4 \\
\hline Марафон & 12,5 & 17,9 & 20,2 & 16,9 \\
\hline Памяти Хангильдина & 4,5 & 20,8 & 20,9 & 15,4 \\
\hline Стабил & 19,1 & 25,8 & 18,5 & 21,1 \\
\hline Томас & 10,8 & 27,7 & 21,3 & 19,9 \\
\hline Ямал 2 & 6,4 & 32,1 & 24,3 & 20,9 \\
\hline \multicolumn{5}{|c|}{ Увинский ГСУ } \\
\hline Аксайский усатый & 27,4 & 16,0 & 15,2 & 19,5 \\
\hline Красноус & 22,2 & 17,5 & 14,0 & 17,9 \\
\hline Марафон & 21,4 & 9,8 & 8,6 & 13,3 \\
\hline Памяти Хангильдина & 23,3 & 17,0 & 15,9 & 18,7 \\
\hline Стабил & 28,0 & 23,3 & 14,8 & 22,0 \\
\hline Томас & 28,9 & 19,7 & 12,5 & 20,4 \\
\hline Ямал 2 & 24,4 & 19,7 & 13,0 & 19,0 \\
\hline \multicolumn{5}{|c|}{ Сарапульский ГСУ } \\
\hline Аксайский усатый & 38,3 & 15,9 & 25,2 & 26,5 \\
\hline Красноус & 36,4 & 11,3 & 19,2 & 22,3 \\
\hline Марафон & 32,3 & 12,8 & 25,3 & 23,5 \\
\hline Памяти Хангильдина & 34,8 & 15,0 & 23,7 & 24,5 \\
\hline Стабил & 40,2 & 14,1 & 19,1 & 24,5 \\
\hline Томас & 41,0 & 15,0 & 21,7 & 25,9 \\
\hline Ямал 2 & 40,6 & 13,5 & 22,2 & 25,4 \\
\hline \multicolumn{5}{|c|}{ Можгинский ГСУ } \\
\hline Аксайский усатый & 26,8 & 38,7 & 19,8 & 28,4 \\
\hline Красноус & 27,8 & 28,1 & 15,8 & 23,9 \\
\hline Марафон & 34,0 & 35,5 & 20,2 & 29,9 \\
\hline Памяти Хангильдина & 30,0 & 34,4 & 19,7 & 28,0 \\
\hline Стабил & 27,8 & 35,3 & 20,2 & 27,8 \\
\hline Томас & 26,1 & 34,4 & 16,4 & 25,6 \\
\hline Ямал 2 & 33,4 & 36,3 & 16,8 & 28,8 \\
\hline
\end{tabular}

только два сорта - Стабил - 22,0 ц/га и Томас $-20,4$ ц/га.

На Сарапульском ГСУ в 2014 г. была получена высокая урожайность у сортов Томас 41,0 ц/га, Ямал 2 - 40,6 ц/га, Стабил - 40,2 ц/ га. В 2015 г. два сорта - Памяти Хангильдина и Томас сформировали урожайность 15,0 ц/га, у сорта Аксайский усатый урожайность 15,9 ц/ га была самой высокой среди изучаемых сортов. В 2016 г. по продуктивности выделились сорта Марафон - 25,3 ц/га и Аксайский усатый - 26,5 ц/га. В среднем за три года преимущество по урожайности имели Аксайский усатый - 26,5 ц/га, Томас - 25,9 ц/га, Ямал 2 25,4 ц/га.

На Можгинском ГСУ в 2014 г. три сорта выделились по урожайности - Марафон - 34,0 ц/га и Памяти Хангильдина - 30,0 ц/га. В 2015 г. наиболее высокой урожайностью характеризовались Аксайский усатый - 38,7 ц/га, Ямал 2 - 36,3 ц/га. В 2016 г. выделились сорта Марафон - 20,0 ц/га и Стабил - 20,2 ц/га. В среднем за годы исследований наибольшую урожайность 29,9 ц/га имел Марафон. У сортов Памя- ти Хангильдина, Аксайский усатый и Ямал 2 она была на уровне 28,0 - 28,8 ц/га.

Таким образом, реакция сортов гороха посевного на абиотические условия формированием урожайности была разной на каждом госсортоучастке. На Балезинском ГСУ выделились сорта Стабил и Красноус, которые имели урожайность 21,1 ц/га и 21,4 ц/га соответственно. На Увинском ГСУ самую высокую урожайность 22,0 ц/га обеспечил сорт Стабил. На Сарапульском ГСУ сорт Аксайский усатый с урожайностью 26,5 ц/га превосходил другие сорта. На Можгинском ГСУ преимущество по урожайности - 29,9 ц/га было за сортом Марафон.

Исходя из полученных результатов исследований, сельским товаропроизводителям при выборе сортов гороха посевного необходимо учитывать реакцию сорта формированием урожайности на абиотические условия на конкретном госсортоучастке. 
1. Фатыхов И.Ш. Научные основы системы земледелия Удмуртской Республики / И.Ш. Фатыхов, Е.В. Корепанова // практическое руководство в 4 книгах /. Том Книга 1 Почвенно-климатические условия. Системы обработки почв. - Ижевск, 2015.

2. Фатыхов И.Ш. Современные проблемы в агрономии / И.Ш. Фатыхов, Е.В. Корепанова, В.Г. Колесникова, В.Н. Гореева // учебное пособие для бакалавров, магистров, аспирантов, обучающихся по направлению "Агрономия" и для сельскохозяйственных товаропроизводителей / Министерство сельского хозяйства Российской Федерации, ФГБОУ ВПО "Ижевская ГСХА". - Ижевск, 2014.

3. Фатыхов И.Ш. Элементный состав семян гороха Аксайский усатый 55 в условиях Среднего Предуралья / И.Ш. Фатыхов, А.В. Мильчакова, М.А. Евстафьев // Аграрный вестник Урала. - 2014. - № 8(126). C. 64-67.

4. Фатыхов И.Ш. Влияние срока посева и нормы высева на урожайность гороха Аксайский усатый $55 /$ И.Ш. Фатыхов, А.В. Мильчакова, М.А. Евстафьев // Аграрная наука - инновационному развитию АПК в современных условиях: материалы Всероссийской научно-практической конференции. ФГБОУ ВПО Ижевская ГСХА. - 2013. - С. 147-153.

5. Фатыхов И.Ш. Влияние срока посева гороха Аксайский усатый 55 на урожайность и образование азотофиксирующих клубеньков / И.Ш. Фатыхов, А.В. Мильчакова, М.А. Евстафьев // Аграрный вестник Урала. - 2013. - № 2(108). - С. 7-8.

6. Фатыхов И.Ш. Реакция гороха посевного Аксайский усатый 55 на сроки посева / И.Ш. Фатыхов, А.В. Мильчакова, М.А. Евстафьев // Вестник Башкирского государственного аграрного университета .- 2013. № 3(27). - С. 29-32.

7. Фатыхов И.Ш. Влияние глубины посева на урожайность гороха посевного Аксайский усатый 55 / И.Ш. Фатыхов, А.В. Мильчакова, М.А. Евстафьев // Научное обеспечение развития АПК в современных условиях: Материалы Всероссийской научно-практической конференции. Ижевская государственная сельскохозяйственная академия. - 2011. - С. 166-168.

8. Фатыхов И.Ш. Предпосевная обработка семян гороха Аксайский усатый 55 и производство гороховых / Инновационному развитию АПК - Научное обеспечение: сборник научных статей Международной научно-практической конференции, посвященной 80-летию Пермской государственной сельскохозяйственной академии. $-2010 .-$ С. 240-243.

9. Фатыхов И.Ш. Интенсивная технология возделывания зерновых и зернобобовых культур в Удмуртской Республике / И.Ш. Фатыхов // учебное пособие / Рецензенты: С. М. Малакотина, Ю. Н. Зубарев; Ижевский сельскохозяйственный институт. - Ижевск, 1994.

10. Фатыхов И.Ш. Формирование урожайности гороха Толар в зависимости от календарных сроков посева и метеорологических условий на ГСУ Удмуртской Республики / И. Ш. Фатыхов, Г.Ф. Яковлева // Тезисы докладов научно-производственной конференции профессорско-преподавательского коллектива, посвященная 75-летию Государственности Удмуртии. - 1995. - С. 13-14.

Сведения об авторах:

Фатыхов Ильдус Шамилевич - доктор сельскохозяйственных наук, профессор, e-mail: nir210@mail.ru Корепанова Елена Витальевна - доктор сельскохозяйственных наук, доцент

Сундукова Яна Николаевна - кандидат сельскохозяйственных наук

ФГБОУ ВО «Ижевская государственная сельскохозяйственная академия», г. Ижевск, Россия.

\section{REACTION OF PEA VARIETIES ON ABIOTIC FACTORS}

\section{Fatykhov I.Sh., Korepanova E.V., Sundukova Ya.N.}

Abstract. The problem of reaction of varieties or hybrids of field crops to abiotic factors has always been key in crop production. Further research is needed in this direction because of the advent of new varieties of pea seed. The purpose of the research is to determine the reaction of pea varieties on abiotic conditions in the competitive varietal testing by the formation of productivity on government consignments of the Udmurt Republic. Research tasks: analysis of yields of seven varieties of peas in four state stations; identify the most productive varieties in different abiotic conditions. The object of research: pea varieties Aksayskiy usatyy, Krasnous, Marafon, In memory of Khangildin, Stabil, Tomas, Yamal 2.

Key words: abiotic conditions, variety reaction, variety testing.

\section{Reference}

1. Fatykhov I. Sh. Nauchnye osnovy sistemy zemledeliya Udmurtskoy Respubliki. / I. Sh. Fatykhov, E. V. Korepanova // prakticheskoe rukovodstvo v 4 knigakh /. Tom Kniga 1 Pochvenno-klimaticheskie usloviya. Sistemy obrabotki pochv. [Scientific foundations of farming system of the Udmurt Republic. // practical guide in 4 books. Volume Book 1 Soil and climatic conditions. Soil processing systems). - Izhevsk, 2015.

2. Fatykhov I. Sh. Sovremennye problemy v agronomii. / I. Sh. Fatykhov, E. V. Korepanova, V. G. Kolesnikova, V. N. Goreeva // uchebnoe posobie dlya bakalavrov, magistrov, aspirantov, obuchayuschikhsya po napravleniyu "Agronomiy"'i dlya selskokhozyaystvennykh tovaroproizvoditeley. / Ministerstvo selskogo khozyaystva Rossiyskoy Federatsii. (Modern problems in agronomy. // Manual for bachelors, masters, postgraduates studying in "Agronomy" faculty and for agricultural producers. / Ministry of Agriculture of the Russian Federation). FGBOU VPO “Izhevskaya GSKhA”. - Izhevsk, 2014.

3. Fatykhov I. Sh. Elemental composition of pea seeds of Aksayskiy usatuy 55 in conditions of middle Urals. [Elementnyy sostav semyan gorokha Aksayskiy usatyy 55 v usloviyakh Srednego Preduralya]. / I. Sh. Fatykhov, A.V. Milchakova, M.A. Evstafev // Agrarnyy vestnik Urala. - Agrarian herald of the Urals. - 2014. - №8 (126). - P. 64-67.

4. Fatykhov I.Sh. Vliyanie sroka poseva i normy vyseva na urozhaynost gorokha Aksayskiy usatyy 55. / I.Sh. Fatykhov, A.V. Milchakova, M.A. Evstafev // Agrarnaya nauka - innovatsionnomu razvitiyu APK v sovremennykh usloviyakh: materi- 
aly Vserossiyskoy nauchno-prakticheskoy konferentsii. (Influence of sowing period and the seeding rate on productivity of pea of Aksay usatyy 55 variety. // Agrarian science - innovative development of the agroindustrial complex in modern conditions: proceedings of All-Russian scientific and practical conference). - FGBOU VPO Izhevskaya GSKhA 2013. - P. 147-153.

5. Fatykhov I.Sh. Influence of sowing period of pea of Aksayskiy usatyy 55 on productivity and formation of nitrogenfixing nodules. [Vliyanie sroka poseva gorokha Aksayskiy usatyy 55 na urozhaynost i obrazovanie azotofiksiruyuschikh klubenkov]. / I.Sh. Fatykhov, A.V. Milchakova, M.A. Evstafev // Agrarnyy vestnik Urala. - Agrarian herald of the Urals. - 2013. - №2 (108). - P. 7-8.

6. Fatykhov I.Sh. Reaction of pea of Aksayskiy usatyy 55 variety to sowing period. [Reaktsiya gorokha posevnogo Aksayskiy usatyy 55 na sroki poseva]. / I.Sh. Fatykhov, A.V. Milchakova, M.A. Evstafev // Vestnik Bashkirskogo gosudarstvennogo agrarnogo universiteta. - The Herald of Bashkir State Agrarian University. 2013. - № 3(27). - P. 29-32.

7. Fatykhov I.Sh. Vliyanie glubiny poseva na urozhaynost gorokha posevnogo Aksayskiy usatyy 55. / I.Sh. Fatykhov, A.V. Milchakova, M.A. Evstafev // Nauchnoe obespechenie razvitiya APK v sovremennykh usloviyakh: Materialy Vserossiyskoy nauchno-prakticheskoy konferentsii. (Influence of sowing depth on the productivity of pea of Aksayskiy usatyy 55 variety. // Scientific support of agribusiness development in modern conditions: Proceedings of All-Russian scientific and practical conference). Izhevskaya gosudarstvennaya selskokhozyaystvennaya akademiya. - 2011. - P. 166-168.

8. Fatykhov I.Sh. Predposevnaya obrabotka semyan gorokha Aksayskiy usatyy 55 i proizvodstvo gorokhovykh. / Innovatsionnoти razvitiyu APK - Nauchnoe obespechenie: sbornik nauchnykh statey Mezhdunarodnoy nauchno-prakticheskoy konferentsii, posvyaschennoy 80-letiyu Permskoy gosudarstvennoy selskokhozyaystvennoy akademii. (Presowing treatment of pea seeds of Aksayskiy usatyy 55 variety and peas production. / Innovative development of the argoindustrial complex Scientific provision: a collection of scientific articles of International Scientific and Practical Conference, dedicated to the $80^{\text {th }}$ anniversary of Perm State Agricultural Academy). - 2010. - P. - 240-243.

9. Fatykhov I.Sh. Intensivnaya tekhnologiya vozdelyvaniya zernovykh i zernobobovykh kultur v Udmurtskoy Respublike. / I.Sh. Fatykhov // uchebnoe posobie. [Intensive technology of grain and leguminous crops cultivation in the Udmurt Republic: textbook]. / Retsenzenty: S. M. Malakotina, Yu. N. Zubarev; Izhevskiy selskokhozyaystvennyy institut. Izhevsk, 1994.

10. Fatykhov I.Sh. Formirovanie urozhaynosti gorokha Tolar v zavisimosti ot kalendarnykh srokov poseva i meteorologicheskikh usloviy na GSU Udmurtskoy Respubliki. / I. Sh. Fatykhov, G.F. Yakovleva // Tezisy dokladov nauchnoproizvodstvennoy konferentsii professorsko-prepodavatelskogo kollektiva, posvyaschennaya 75-letiyu Gosudarstvennosti Udmurtii. (Formation of peas yield of Tolar variety, depending on the calendar dates of sowing and meteorological conditions at the GSU of the Udmurt Republic. // Theses of reports of the scientific and production conference of the teaching staff, dedicated to the $75^{\text {th }}$ anniversary of the Statehood of Udmurtia). - 1995. - P. 13-14.

Authors:

Fatykhov Ildus Shamilevich - Doctor of Agricultural sciences, Professor, e-mail: nir210@mail.ru

Korepanova Elena Vitalevna - Doctor of Agricultural sciences, Professor

Sundukova Yana Nikolaevna - Ph.D. of Agricultural Sciences

Izhevsk State Agricultural Academy, Izhevsk, Russia 